\title{
International Neuroblastoma Pathology Classification
}

National Cancer Institute

\section{Source}

National Cancer Institute. International Neuroblastoma Pathology Classification. NCI

Thesaurus. Code C102562.

A classification system established by adopting the original system proposed by Shimada with subsequent revisions. The INPC disting uishes favorable and unfavorable histology groups. 